\title{
Observations of sulfur dioxide uptake and new particle formation in a midlatitude cumulus cloud
}

\author{
J. R. Peter ${ }^{1,}$, S. T. Siems ${ }^{1}$, J. B. Jensen ${ }^{2}$, J. L. Gras ${ }^{3}$, Y. Ishizaka ${ }^{4}$, and \\ J. M. Hacker ${ }^{5,6}$ \\ ${ }^{1}$ School of Mathematical Sciences, Monash University, Clayton, VIC 3800, Australia \\ ${ }^{2}$ National Center for Atmospheric Research, P.O. Box 3000, Boulder, CO 80307-3000, USA \\ ${ }^{3} \mathrm{CSIRO}$ Marine and Atmospheric Research, 107-121 Station Street, Aspendale, VIC 3195, \\ Australia \\ ${ }^{4}$ Hydrospheric Atmospheric Research Center(HyARC) Nagoya University, Chikusa-ku, \\ Nagoya 464-8601, Japan \\ ${ }^{5}$ Airborne Research Australia, P.O. Box 335, Salisbury South, SA 5106, Australia \\ ${ }^{6}$ School of Chemistry, Physics and Earth Sciences, Flinders University, GPO Box 2100, \\ Adelaide, SA 5001, Australia \\ *now at: Institute for Atmospheric Science, School of Earth and Environment, University of \\ Leeds, Leeds LS2 9JT, UK
}

Received: 18 May 2006 - Accepted: 15 June 2006 - Published: 4 August 2006

Correspondence to: J. R. Peter (jpeter@env.leeds.ac.uk)

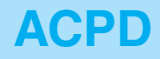

$6,7471-7497,2006$

New particle formation in cloud

J. R. Peter et al.

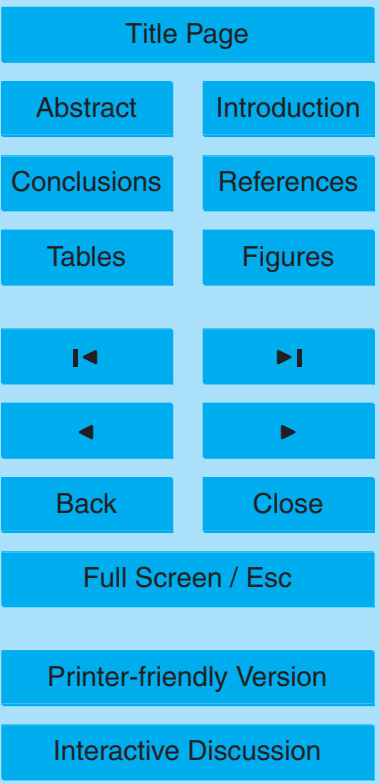




\section{Abstract}

Airborne measurements, obtained during the Asian Aerosol Characterisation Experiment (ACE-Asia), of $\mathrm{SO}_{2}$ and condensation nuclei (CN) concentrations were made in the local environment of a cumulus cloud band. Conserved quantities, wet equivalent

5 potential temperature $\theta_{q}$, and total water content $Q$, were used to identify the sources of air detrained on the downwind side of the cumulus band. It was found that $\sim 65 \%$ of the detrained air originated from below cloud base and the remainder was air that had been entrained from the free troposphere upwind of the cloud and subsequently been detrained. Calculation of the sources of the detrained air parcels enabled a prediction of the concentration of $\mathrm{SO}_{2}$ and $\mathrm{CN}$, assuming that $\mathrm{SO}_{2}$ and $\mathrm{CN}$ experienced no processing within cloud. A comparison of the predicted concentration of $\mathrm{SO}_{2}$ and $\mathrm{CN}$ was made with those observed. The concentration of $\mathrm{SO}_{2}$ observed was less than predicted and the amount of $\mathrm{SO}_{2}$ scavenged within cloud was calculated. The $\mathrm{CN}$ concentration observed was also less than predicted and, moreover, inclusion of the loss of $\mathrm{CN}$ to cloud droplets due to Brownian scavenging resulted in an enhanced decrease of the number concentration of $\mathrm{CN}$ predicted. Clear air regions around the cloud exhibited no indication of being a major source of new particles. It was concluded that new particles were formed within cloud.

\section{Introduction}

20 The ubiquitous presence of aerosol in the atmosphere modifies the amount of radiation reaching the Earth's surface. In general, the modification is to cool the Earth's climate, to a degree that it may offset climate warming due to greenhouse gases (Coakley et al., 1983; Charlson et al., 1992). Two processes have been identified that lead to the cooling, (1) the "direct effect" of enhanced scattering of shortwave radiation due to the increased loading of aerosol in the atmosphere, and (2) the "indirect effect" of enhanced cloud reflectivity and lifetime, due to the higher concentration of smaller

\section{New particle formation in cloud}

J. R. Peter et al.

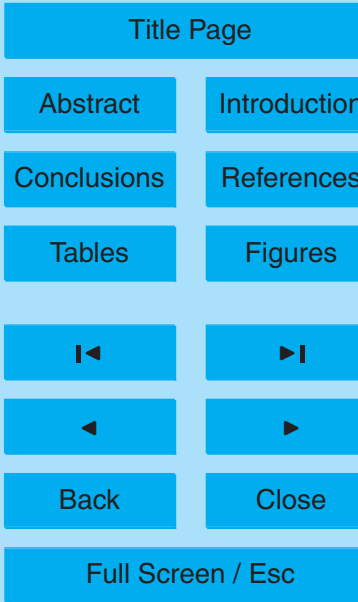

Printer-friendly Version

Interactive Discussion 
cloud droplets as compared to clouds formed in a cleaner atmosphere (Twomey, 1977; Albrecht, 1989).

Aerosol particles in the remote marine boundary layer (MBL) are composed primarily of sea-salt (produced by agitation of the sea surface) and non-sea-salt (nss) sulfate.

5 Nss-sulfate is primarily formed via gas-phase and aqueous-phase heterogeneous oxidation of $\mathrm{SO}_{2}$. The aqueous-phase oxidation of $\mathrm{SO}_{2}$ in cloud droplets proceeds via reaction with hydrogen peroxide $\left(\mathrm{H}_{2} \mathrm{O}_{2}\right)$ or ozone $\left(\mathrm{O}_{3}\right)$ depending on the $\mathrm{pH}$ of the solution (e.g. Seinfeld and Pandis, 1998) to produce additional dissolved droplet mass (sulfate). The addition of mass to aerosol due to in-cloud oxidation of $\mathrm{SO}_{2}$ has been 10 attributed to the aerosol number size distribution exhibiting a minimum near $0.06 \mu \mathrm{m}$ between two peaks near 0.02 and $0.09 \mu \mathrm{m}$ radius (Hoppel et al., 1986). The minimum occurs at the smallest size at which aerosol are able to activate to become cloud droplets. All aerosol above this size are known as cloud condensation nuclei (CCN). As cloud droplets, the CCN scavenge additional trace material such that when the cloud 15 droplets evaporate the CCN form a separate mode at around $0.09 \mu \mathrm{m}$, while the unactivated condensation nuclei $(\mathrm{CN})$ remain in the mode around $0.02 \mu \mathrm{m}$. Aqueous phase oxidation of $\mathrm{SO}_{2}$ to sulfate and the subsequent modification of the aerosol size distribution result in the dry aerosol being a more efficient light scatterer (Yuskiewicz et al., 1999), which has a subsequent cooling effect on climate (Lelieveld and Heintzenberg, 20 1992).

Despite the important role clouds have in transforming and redistributing chemical species in the atmosphere, observational quantification of the amount of sulfate produced in clouds remains relatively undetermined. The difficulty in quantifying the proportion of sulfate due to in-cloud processing is mainly due to atmospheric mixing that makes identification of the air mass sources difficult. Previous attempts to measure the amount of sulfate produced in cloud have measured the decay rate of hydrogen peroxide $\left(\mathrm{H}_{2} \mathrm{O}_{2}\right)$ in the presence of a released quantity of $\mathrm{SO}_{2}$ (e.g. Gervat et al., 1988) in the atmosphere, or measured the amount of sulfate contained in cloud water directly (Hegg and Hobbs, 1982). Measuring the amount of sulfate in cloud water directly, is unable to

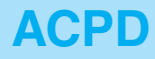

$6,7471-7497,2006$

\section{New particle formation in cloud}

J. R. Peter et al.

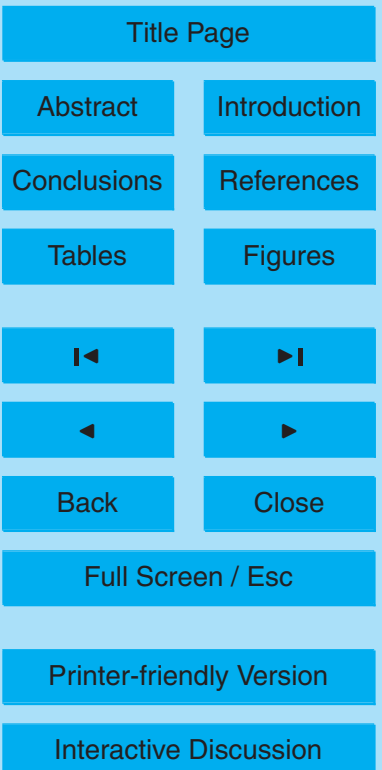

EGU 
resolve the sulfate produced from in-cloud reactions from the sulfate contained in the CCN.

Another climate-relevant modification of the aerosol size distribution can occur due to formation of new particles near clouds. Several investigators have observed new par5 ticle formation either in the outflow of clouds (Wiedensohler et al., 1997; Clarke et al., 1998; Clement et al., 2002; Twohy et al., 2002), above cloud top (Weber et al., 2001), or in both regions (Perry and Hobbs, 1994). Fresh particles are nucleated when gaseous precursor species, sulfur dioxide $\left(\mathrm{SO}_{2}\right)$ and dimethyl sulfide (DMS), are present in sufficient concentrations. Under conditions of high relative humidity, low pre-existing 10 aerosol surface area and low temperature, $\mathrm{SO}_{2}$ and DMS will oxidize with hydroxyl radicals $(\mathrm{OH})$ to form sulfuric acid $\left(\mathrm{H}_{2} \mathrm{SO}_{4}\right)$. New particles are then formed via homogeneous bi-molecular nucleation of $\mathrm{H}_{2} \mathrm{SO}_{4}$ and $\mathrm{H}_{2} \mathrm{O}$. Downwind of precipitating clouds, the lower aerosol surface area (caused by precipitation scavenging) and transport of precursor gases creates conditions conducive for particle nucleation (Perry and Hobbs, 15 1994). Above cloud, enhanced actinic fluxes produce an increased $\mathrm{OH}$ concentration resulting in particle nucleation (Perry and Hobbs, 1994; Weber et al., 2001).

Several studies have, however, observed production of new particles within clouds (Radke and Hobbs, 1991; Hegg et al., 1991). The fact that enhanced numbers of particles are observed in clouds is surprising as the large in-cloud droplet surface area provides an enormous sink for gas-phase $\mathrm{H}_{2} \mathrm{SO}_{4}$. In a later study, Hegg (1991) proposed that enhanced production of $\mathrm{OH}$ within cloud (due to the increased actinic flux, Madronich, 1987) could promote homogeneous heteromolecular nucleation of $\mathrm{H}_{2} \mathrm{SO}_{4}$, thereby providing the necessary acid supersaturation for new particle formation.

In this paper we use conserved variables, wet equivalent potential temperature $\left(\theta_{q}\right)$ 25 and total water $(Q)$ to identify the sources of $\mathrm{SO}_{2}$ and unactivated $\mathrm{CN}$ in air detraining from a cumulus cloud. Analysis of the mixing properties of the conserved tracers enables a prediction of the concentration of $\mathrm{SO}_{2}$ and $\mathrm{CN}$ particles to be made assuming that neither have been influenced by cloud. Observed concentrations of $\mathrm{SO}_{2}$ and $\mathrm{CN}$ in the detrained air are then made with the predictions of these quantities, determined via

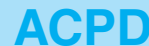

$6,7471-7497,2006$

\section{New particle formation in cloud}

J. R. Peter et al.

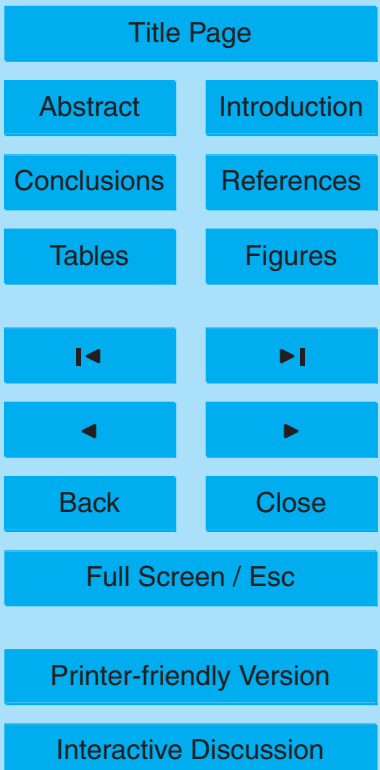

EGU 
mixing analysis, to determine the influence of the cloud on $\mathrm{SO}_{2}$ and $\mathrm{CN}$ concentrations.

\section{Experimental details}

The Airborne Research Australia (ARA) Beechcraft King-Air was fitted with TSI-3025 and TSI-3010 condensation nuclei (CN) counters to measure total concentrations of particles with radii greater than $1.3 \mathrm{~nm}$ and $6 \mathrm{~nm}$ respectively. Particle Measuring Systems (PMS) ASASP and FSSP optical particle counters were used to examine accumulation mode aerosol and cloud droplets. The ASASP is equipped with a heated inlet and measures particles in the size range $0.065-1.5 \mu \mathrm{m}$ over 15 size bins. The FSSP, which was corrected for dead time losses, measures cloud droplets in the size range $10 \quad 1.5-23.5 \mu \mathrm{m}$ over 22 size bins. A PMS 2D-C optical array probe was used to measure droplet spectra in the radius range $37.5-400 \mu \mathrm{m}$ over 30 size bins. The ASASP data are $1 \mathrm{~Hz}$ averages of $64 \mathrm{~Hz}$ data, while the FSSP and 2-D-C measurements are $1 \mathrm{~Hz}$ averages of $4 \mathrm{~Hz}$ data. Sulfur dioxide was measured with a Thermo Environmental Systems Inc., Model 43S Pulsed Fluorescent Ambient $\mathrm{SO}_{2}$ analyzer. $\mathrm{SO}_{2}$ measurements are $1 \mathrm{~Hz}$ averages of $64 \mathrm{~Hz}$ data.

On 24 April 2004, the King Air encountered a band of cumulus, south-east of Kyushu. The cloud was located at approximately $30^{\circ} 30^{\prime} \mathrm{N}, 133^{\circ} 15^{\prime} \mathrm{E}$. The King Air flew six horizontal transects of the cumulus oriented east-west, roughly perpendicular to the northsouth orientation of the cloud band. Cloud base was at $540 \mathrm{~m}(925 \mathrm{hPa})$, cloud top at $3200 \mathrm{~m}(675 \mathrm{hPa})$. The wind direction in the sub-cloud layer was from the north-east, and from the west in the free troposphere.

\section{New particle formation in cloud}

J. R. Peter et al.

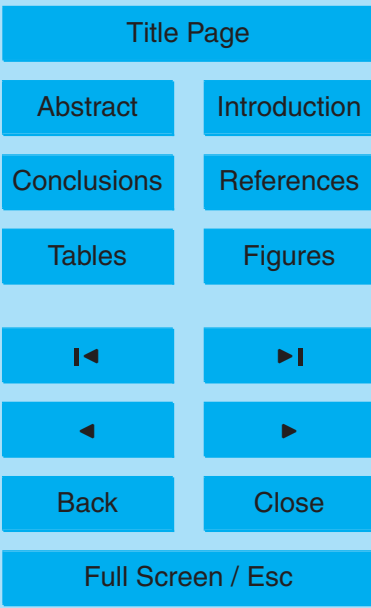

Printer-friendly Version

Interactive Discussion 


\section{Observations}

\subsection{Mixing analysis}

The analysis presented in this paper relies fundamentally on knowledge of how conserved tracers mix, which is illustrated through the use of conserved variable diagrams 5 (Paluch, 1979). If two parcels (labelled $a$ and $b$ ) identified by two conserved parameters, in this case $\theta_{q}$ and $Q$, are mixed then the resulting mixed parcel (labelled mix) will have,

$\theta_{q, \text { mix }}=(1-F) \theta_{q, a}+(F) \theta_{q, b}$

$Q_{\text {mix }}=(1-F) Q_{a}+(F) Q_{b}$

10 where $F$ represents the fraction of mass of the final mixture that was originally in parcel $b$. A mixing diagram of $\left\{\theta_{q}, Q\right\}$ samples obtained during the flight is shown in Fig. 1. One $\mathrm{Hz}\left\{\theta_{q}, Q\right\}$ samples are shown for clear air, cloudy air and a sounding made in clear air in the upwind side of the cloud band. Here, clear (cloudy) air is defined by all $64 \mathrm{~Hz}$ samples within a $1 \mathrm{~Hz}$ averaged sample having a $\mathrm{LWC} \leq 0.01 \mathrm{~g} \mathrm{~kg}^{-1}\left(\mathrm{LWC} \geq 0.1 \mathrm{~g} \mathrm{~kg}^{-1}\right)$.

15 The cloudy and clear air samples were obtained from an aircraft penetration made across the cloud at a constant altitude. The clear air samples were obtained in air that had been detrained on the downwind side of the cloud. The cloudy and clear air samples fall on a straight line between the cloud base sample and a level on the sounding termed the Primary Source of Entrained Air (PSEA). The linearity of the cloudy and

clear air samples indicates that air at the flight level is a mixture of air that originated from below cloud base and the PSEA. Furthermore, because $Q$ mixes linearly and $\theta_{q}$ nearly linearly, the fraction of sub-cloud air contained in the cloudy and clear air samples is given by (Jensen et al., 1985),

$F \approx \frac{1}{2}\left(\frac{\theta_{q}-\theta_{q, e}}{\theta_{q, s}-\theta_{q, e}}+\frac{Q-Q_{e}}{Q_{s}-Q_{e}}\right)$

\section{New particle formation in cloud}

J. R. Peter et al.

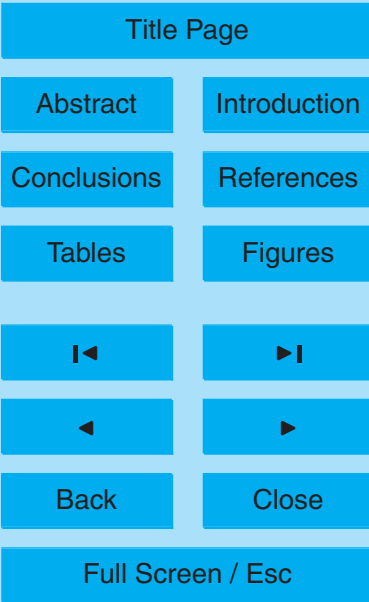

Printer-friendly Version

Interactive Discussion 
where subscripts $s$ and $e$ refer to sub-cloud and entrained (PSEA) air respectively.

The forcing mechanism of the cloud band was presented extensively in Peter et al. (2006), however, the main points are summarized here. Figure 2 illustrates the forcing and dynamics of the observed cumulus band. Sub-cloud air on the western extent of 5 the cloud band had an increased buoyancy compared to BL air on the eastern side of the cloud band. The air on the eastern edge of the cloud band had experienced cooling due to evaporation of precipitation into the BL. Additionally, the sea surface exhibited a temperature gradient with cooler surface temperature on the eastern side of the cloud band. The combination of evaporative cooling and lower SST resulted in a cold pool 10 forming on the eastern extent of the cloud band, such that air on the western extent was lifted and made its way into cloud base. The cloud detrained air sampled downwind of the cumulus, the thermodynamic characteristics of which is represented by the closed circles in Fig. 1, thus consisted of air that had originated from below cloud base and was transported vertically in cloud then subsequently mixed with air entrained into the cloud from the PSEA. The resulting mixture of air was then detrained on the downwind side of the cloud band. The relative fraction of air that had originated from sub-cloud and the PSEA is represented schematically in Fig. 2 and is quantitatively determined by Eq. (2).

The use of the conserved variable diagram has provided a method whith which to explicitly determine the sources of the cloud detrained air. Knowledge of the sources of the detrained air is important as it enables determination of the effect of cloud processing on aerosol and gas species. If the cloud has no effect on aerosol and gas species then they will mix in the same fraction as the conserved tracers, therefore discrepancies between the concentration predicted via mixing arguments and the observed concentration can be attributed to cloud processing. Mathematically, if a species has a concentration $C_{s}$, in the sub-cloud layer and a concentration $C_{e}$, at the PSEA, then the predicted (labelled pre) concentration is given by,

$C_{\text {pre }}=(F) C_{s}+(1-F) C_{e}$

\section{New particle formation in cloud}

J. R. Peter et al.

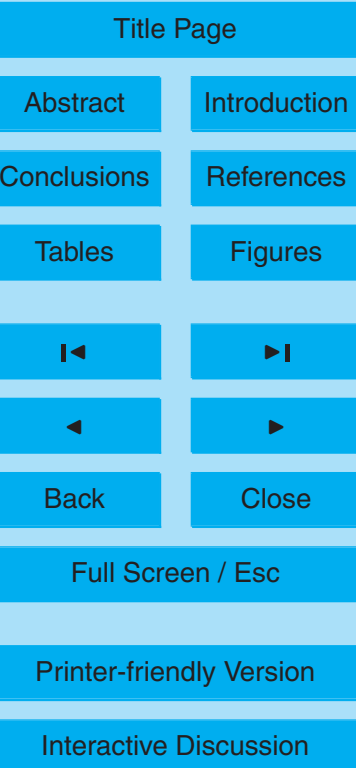


The loss attributed to cloud processing (labelled $c p$ ) is then,

$C_{c p}=C_{\text {pre }}-C_{\text {obs }}$

We use the above arguments to predict the concentration of $\mathrm{SO}_{2}$ and $\mathrm{CN}$ in the detrained air and then compare the prediction with observations to examine cloud processing of these species.

\subsection{Sulfur dioxide}

\subsubsection{Amount of $\mathrm{SO}_{2}$ processed by cloud}

The mixing ratio of sulfur dioxide in the source regions (sub-cloud and PSEA) and the detrained region are shown in Table 1 . The difference between the predicted and observed $\mathrm{SO}_{2}$ concentration is the amount of $\mathrm{SO}_{2}$ that has been lost in cloud, most likely due to aqueous phase oxidation of $\mathrm{SO}_{2}$ to sulfate. The predicted mixing ratio of $\mathrm{SO}_{2}$ in the detrained air downwind of the cumulus band was $5.81 \pm 0.17 \mu \mathrm{g} \mathrm{m}^{-3}$ (assuming the fraction of air originating from sub-cloud was $F=0.64$ ), while the measured concentration was $4.57 \pm 0.12 \mu \mathrm{g} \mathrm{m}^{-3}$. The implication is that $1.24 \pm 0.17 \mu \mathrm{g} \mathrm{m}^{-3}$ of $\mathrm{SO}_{2}$ has been 15 scavenged.

The result compares quite favorably with (Liu et al., 1993), who observed 1.54.6 ppbv (6-18 $\left.\mu \mathrm{g} \mathrm{m}^{-3}\right) \mathrm{SO}_{2}$ converted to sulfate in cloud droplets for a cumulus cloud observed over Ontario, Canada. For an orographic cloud Birmili et al. (1999) observed a mass increase (to the aerosol spectrum due to sulfate production) of approximately 20 $1.4 \mu \mathrm{g} \mathrm{m}^{-3}$. Hegg et al. (1984) measured $1.0 \pm 0.3 \mu \mathrm{g} \mathrm{m}^{-3}$ sulfate produced within cumulus and stratocumulus (SCu) clouds. O'Dowd et al. (1998) modeled a case of aerosol processing by a SCu, and found $0.44 \mu \mathrm{g} \mathrm{m}^{-3}$ of sulfate to be produced in cloud. Recently, Husain et al. (2004) used Se as a tracer to determine the amount of $\mathrm{SO}_{4}^{2-}$ produced within cloud and thereby calculate in-cloud loss of $\mathrm{SO}_{2}$. They ob25 tained concentrations in the range $0.1-1.0 \mathrm{ppb}\left(0.26-2.6 \mu \mathrm{g} \mathrm{m}^{-3} \mathrm{STP}\right)$ of $\mathrm{SO}_{2}$ oxidized in cloud. Their method utilised 5-min average measurements of aerosol Se, however,

\section{New particle formation in cloud}

J. R. Peter et al.

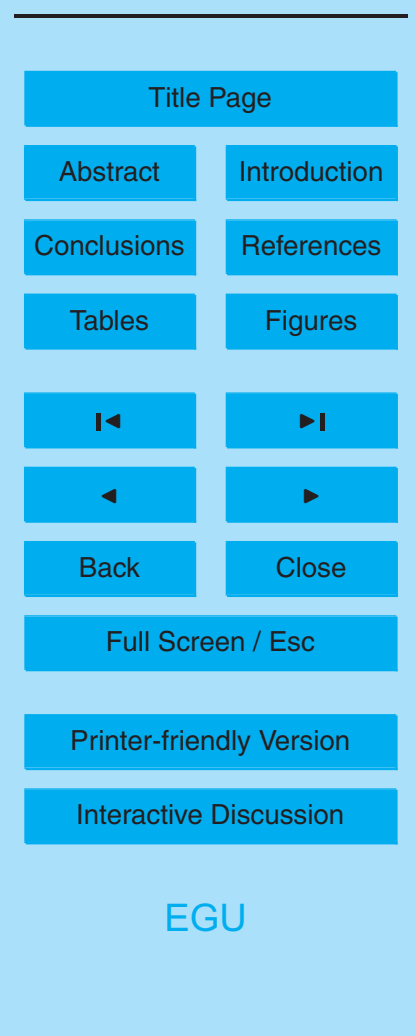


the present method relies on measurements generally obtainable on most research aircraft (temperature, water vapour mixing ratio and liquid water content) at larger frequency $(\sim 1 \mathrm{~Hz})$. Dual calculations of $\mathrm{SO}_{2}$ uptake within a cloud using both techniques would be beneficial.

5 The amount of $\mathrm{SO}_{2}$ scavenged within cloud can provide rate constants for aqueous phase oxidation of $\mathrm{SO}_{2}$ with $\mathrm{H}_{2} \mathrm{O}_{2}$ and $\mathrm{O}_{3}$. Additionally, it can provide a measure of parcel in-cloud residence time, which is a vital parameter to make meaningful comparisons of model simulations of cloud droplet size distributions with observations. The time a parcel spends in-cloud may be significantly different from the cloud lifetime deter10 mined, say, from radar measurements. Since the use of mixing fractions to determine the amount of $\mathrm{SO}_{2}$ converted to sulfate within cloud agrees well with previous calculations, the technique should be investigated further for applications to in-cloud parcel residence time.

\subsubsection{Effect of sulfate production on CCN}

15 When a cloud droplet evaporates it will leave a residue aerosol particle consisting of the initial CCN on which the droplet formed plus sulfate produced in the droplet due to oxidation of $\mathrm{SO}_{2}$. The production of sulfate will increase the mass of the residual aerosol particle relative to the $\mathrm{CCN}$ on which the cloud droplet formed. To investigate how sulfate production will effect the aerosol size distribution, it was assumed that the $\mathrm{SO}_{2}$ scavenged within cloud was converted to ammonium sulfate, $\left(\mathrm{NH}_{4}\right)_{2} \mathrm{SO}_{4}$. In the atmosphere, the evaporated droplet will leave behind an aerosol in a molecular form somewhere between $\mathrm{H}_{2} \mathrm{SO}_{4}$ and $\left(\mathrm{NH}_{4}\right)_{2} \mathrm{SO}_{4}$ depending on the availability of ammonia (Pilinis and Seinfeld, 1987). Measurements by (Bahreini et al., 2003), during the ACEAsia campaign, estimated the molar ratio of $\mathrm{NH}_{4}^{+} / \mathrm{SO}_{4}^{2-}$ to be 1.9 for air masses which 25 had influence from Korean emissions. The air mass examined here had similar origins to those investigated by (Bahreini et al., 2003); it thus reasonable to assume that the majority of scavenged $\mathrm{SO}_{2}$ had been converted to ammonium sulfate.

The number of aerosol activated (CCN) was determined from the cloud droplet num-

\section{New particle formation in cloud}

J. R. Peter et al.

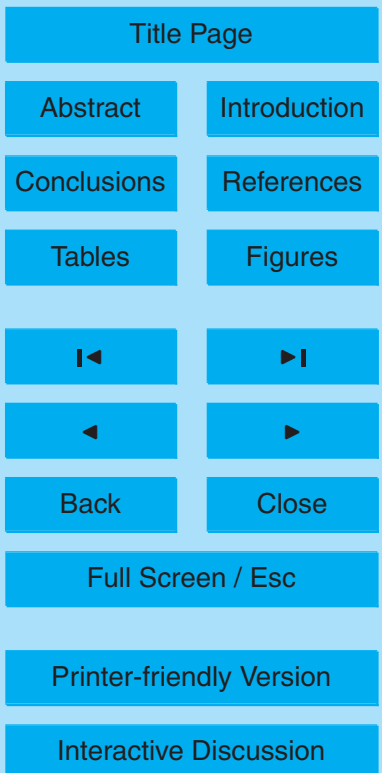


ber concentration (CDNC). At cloud base, the CDNC measured with the FSSP-100 probe was $620 \mathrm{~cm}^{-3}$, but in cloud, $800 \mathrm{~m}$ above cloud base, it was reduced to $470 \mathrm{~cm}^{-3}$. The reduction in CDNC with height is indicative of entrained air diluting the CDNC. The number of CCN, calculated as an average of the CDNC, at two levels in cloud was

$5540 \mathrm{~cm}^{-3}$. The ASASP measured concentration of aerosol, in the cloud in-flow region below cloud base was $370 \mathrm{~cm}^{-3}$. This implies that all of the ASASP measured aerosol served as CCN, and a fraction of the aerosol measured by the CN counters. From a plot of the cumulative sub-cloud aerosol size distribution (not shown), it was calculated that the minimum size of aerosol activated at cloud base was $r_{p} \approx 0.04 \mu \mathrm{m}$. This 10 assumes that all aerosol larger than this radius are soluble and able to serve as CCN.

The ammonium sulfate was distributed to the activated fraction of aerosol according to number concentration. The aerosol was assumed to be internally mixed and of uniform chemical composition. Since particles smaller than the lowest size resolution of the ASASP were activated, some of the mass was distributed among aerosol 15 not detected by it. As there was no size information available for the CCN below the lowest size resolution of the ASASP, only the fraction of mass added to ASASP detectable aerosol was considered. This meant that each size class $i$, gained a mass governed by its number concentration $\left(\mathrm{n}_{i} / 540 \mu \mathrm{g}\right)$. Distribution of $\mathrm{SO}_{2}$ mass according to aerosol number concentration results in the ratio of scavenged gas to particle mass being inversely proportional to particle radius (i.e. smaller $\mathrm{CCN}$ increase their radius more due to gas scavenging than the larger CCN). Model (e.g. Bower and Choularton, 1993; Choularton et al., 1997) and experimental (Krämer et al., 2000) studies indicate that the smallest activated aerosol particles are most significantly affected by cloud processing. This is because the scavenging ratio (mass of gas scavenged to mass of aerosol) is highest for the smaller particles. Apportioning the mass according to number concentration conforms to this behavior. As pointed out by Leaitch (1996), distributing the available sulfate among the aerosol population according to number concentration assumes that the growth is controlled by the surface area of the cloud droplets.

\section{New particle formation in cloud}

J. R. Peter et al.

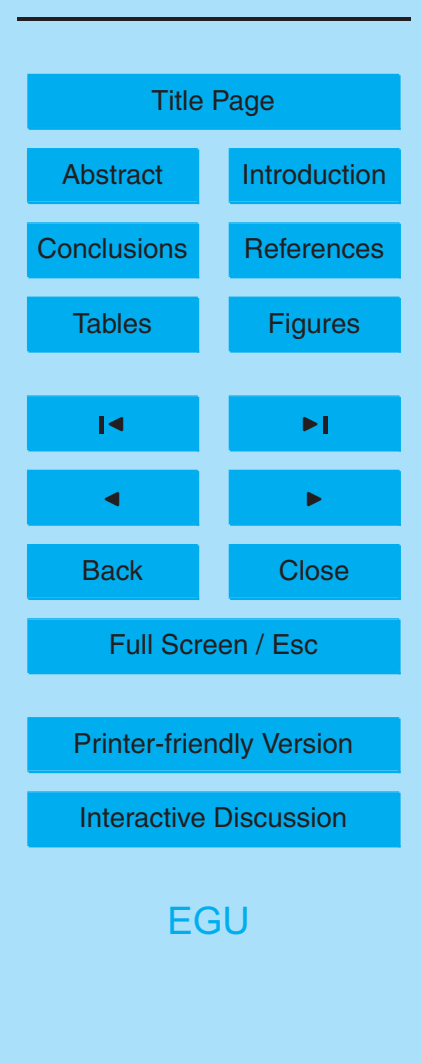


The spectra predicted by mixing, predicted after the mass addition of sulfate and observed are shown in Fig. 3. Figure 3 shows that the majority of the predicted mass addition of sulfate (open squares) occurs in the first three size classes of the ASASP and, aerosol in these size classes may grow enough such that they may be transferred 5 to a larger size class, i.e. there will be a net loss of particles from ASASP size classes one-to-three. However, the lowest size resolved by the ASASP was above that of the minimum size of activated CCN, which would result in a gain in the number of ASASP size classes one-to-three. Because the smallest CCN grow the most after addition of sulfate, there is a net production of particles in the smallest ASASP size classes.

Coalescence of cloud droplets reduces the concentration of CCN. The response of the aerosol particle size distribution to the competing mechanisms of, (1) growth of particles due to sulfate production and (2) particle loss, due to droplet coalescence is illustrated in Fig. 3. Except for the first two ASASP size classes, the observed aerosol particle concentration is consistently less than the predicted concentration, 15 due to droplet coalescence (Peter et al., 2006). Since, the concentration of aerosol particles in the first two size classes is nearly equal to the predicted concentration, the addition of mass to these size classes has compensated for their loss due to cloud droplet coalescence.

\subsection{Condensation nuclei}

20 The concentration of CN measured by the TSI-3025 and TSI-3010 probes in the source regions (sub-cloud and PSEA) and the detrained region are shown in Table 1. As was calculated for $\mathrm{SO}_{2}$, the difference between the predicted and observed CN concentrations is the concentration of $\mathrm{CN}$ that has been lost in cloud. Unlike $\mathrm{SO}_{2}$, however, which undergoes aqueous phase oxidation, $\mathrm{CN}$ diffuse via Brownian motion to cloud droplets. 25 The ratio of the predicted $\mathrm{CN}$ concentration to the observed is shown in Fig. 4 (horizontal red lines). The ratios were calculated from the differential concentration, not from the cumulative concentration which is output from the probes. The differential concentration for the TSI-3025 $\left(r_{p} \geq 1.3 \mathrm{~nm}\right)$ is the difference of the concentrations measured by

\section{New particle formation in cloud}

J. R. Peter et al.

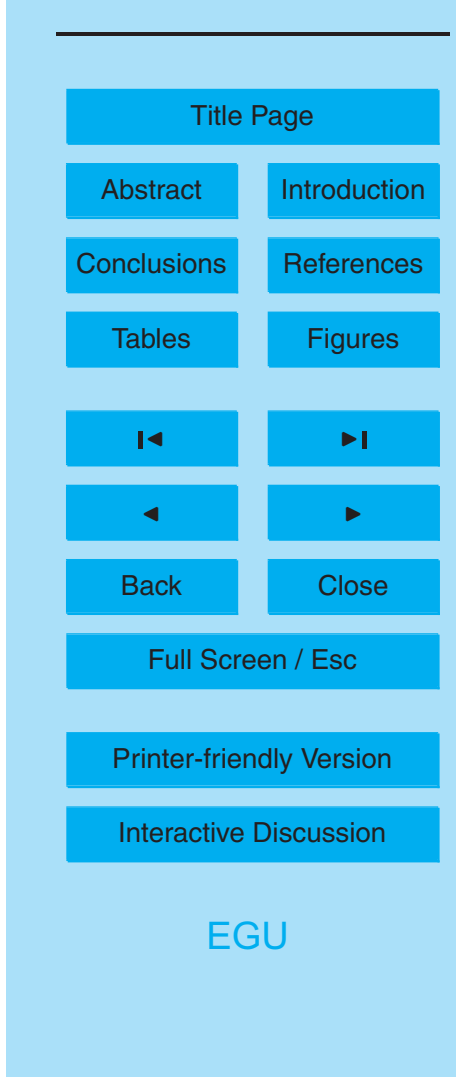


the TSI-3025 and TSI-3010. The differential concentration for the TSI-3010 $\left(r_{p} \geq 6 \mathrm{~nm}\right)$ is the difference of the concentrations measured by the TSI-3010 and ASASP probes. Figure 4 shows the number concentration of $\mathrm{CN}$ predicted by mixing is greater than observed, presumably due to Brownian scavenging by cloud droplets.

5 A model was used to determine if diffusional loss of unactivated particles to cloud droplets could account for the observed loss of particles measured by the $\mathrm{CN}$ counters as compared to the predicted concentration (see Table 1). Aerosol particles, interstitial in the cloudy air, are assumed to collide with cloud droplets and are removed from cloud interstitial air. The rate of such removal is governed by coagulation theory. Let $n_{a}\left(r_{a}, t\right)$ 10 and $n_{d}(x, t)$ represent the aerosol and cloud droplet number distributions respectively. The loss rate of aerosol particles per unit volume of air due to diffusional loss to cloud droplets is determined by,

$-\frac{\partial n_{a}\left(r_{a}, t\right)}{\partial t}=n_{a}\left(r_{a}, t\right) \int_{0}^{\infty} K\left(r_{a}, x\right) n_{d}(x, t) d x$

where $K\left(r_{a}, x\right)$ is the collection coefficient. Assuming that aerosol particles diffuse to the cloud droplets via Brownian motion, the collection coefficient, which represents collisions between an interstitial aerosol and the cloud drops, can be written as (Seinfeld and Pandis, 1998, p.660):

$K\left(r_{1}, r_{2}\right)=4 \pi\left(r_{1}+r_{2}\right)\left(D_{1}+D_{2}\right) \beta$

where $r_{i}$ and $D_{i}$ are the radius and diffusion coefficient of particle $i$, respectively. The correction factor, $\beta$, to account for the transition and free-molecular regimes is that proposed by Dahneke (1983), namely,

$$
\begin{aligned}
& \beta=\frac{1+K n_{D}}{1+2 K n_{D}\left(1+K n_{D}\right)} \\
& K n_{D}=\frac{2\left(D_{1}+D_{2}\right)}{\bar{c}_{12} r_{12}}
\end{aligned}
$$

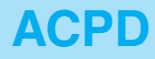

$6,7471-7497,2006$

\section{New particle formation in cloud}

\section{J. R. Peter et al.}

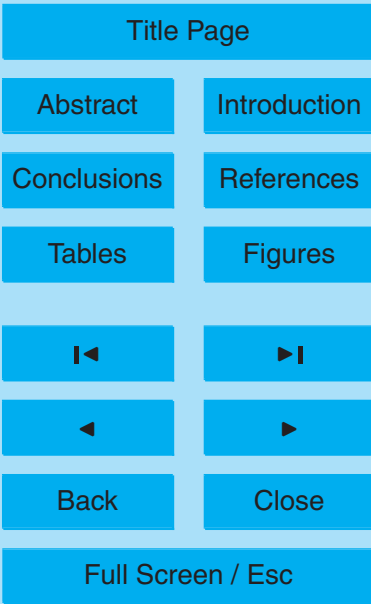

Printer-friendly Version

Interactive Discussion 
where $r_{12}=r_{1}+r_{2}, \bar{c}_{12}=\sqrt{c_{1}^{2}+c_{2}^{2}}$ and $c_{i}=\left(\frac{8 k T}{\pi m_{i}}\right)^{1 / 2}$. Here, $c_{i}$ represents the mean free path of either the aerosol or cloud droplet. If the cloud drop number size distribution is stationary (i.e. if the drop distribution that the aerosol are diffusing is constant in time) then the number of aerosol $n\left(r_{a}, t\right)$ remaining after a time $t$, will be,

$5 \quad n\left(r_{a}, t\right)=n\left(r_{a}, 0\right) \exp [-\Lambda(r, t)]$

where $\Lambda$ is the scavenging coefficient,

$\Lambda(r, t) \equiv-\frac{1}{n} \frac{\partial n_{a}\left(r_{a}, t\right)}{\partial t}=\int_{0}^{\infty} K\left(r_{a}, x\right) n_{d}(x, t) d x$

Equations (9) and (10) were solved with the assumption of a stationary droplet size distribution. The droplet size distribution $n_{d}(x, t)$, was determined from FSSP measure10 ments during the cloud penetration at the same altitude ( $800 \mathrm{~m}$ above cloud base) as the $\mathrm{SO}_{2}$ and $\mathrm{CN}$ observations. Although the cloud droplet size distribution will change due to coalescence and mixing of sub-saturated entrained air from the PSEA, the effective radius and number concentration at this level was found to be representative (i.e. comparable number concentrations and effective radii) of the droplet size distribution for cloud traverses at higher altitudes. Brownian diffusion scavenging of $\mathrm{CN}$ to accumulation mode aerosol in clear air detrained downwind of the cloud band was neglected as it was found to be insignificant when compared with scavenging to cloud droplets.

The results of the calculation are shown in Fig. 4. The series of dashed red curves represent the ratio of, the number concentration of $\mathrm{CN}$ predicted due to mixing and Brownian diffusion to the number concentration observed. Curves are shown for incloud times of $1,5,10$ and $60 \mathrm{~min}$, representative of a potential parcel in-cloud lifetime. It can be seen that even for an in-cloud time of one minute most, if not all, of the smallest $\mathrm{CN}$ particles will be scavenged by Brownian diffusion. In-cloud updraft speeds were $\sim 5 \mathrm{~m} \mathrm{~s}^{-1}$, so at the flight altitude ( $\sim 900 \mathrm{~m}$ above cloud base) an in-cloud parcel resi25 dence time of $\sim 3$ min would be an absolute minimum. The fact that $\mathrm{CN}$ are observed in the detrained cumulus air is indicative of new particle formation. Due to the large

\section{New particle formation in cloud}

J. R. Peter et al.

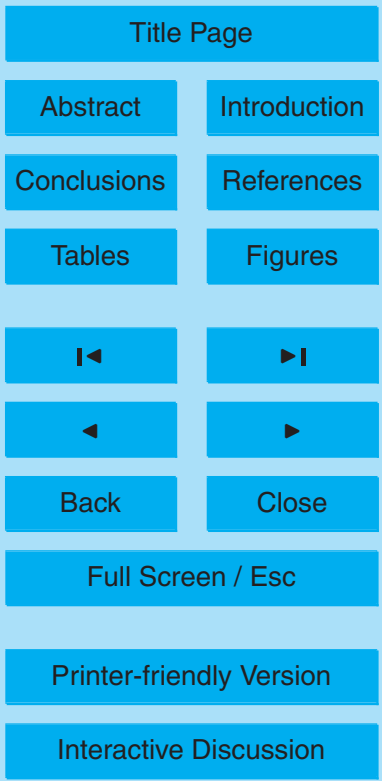


discrepancy between the predicted and observed concentration when Brownian diffusion was taken into account we considered the possibility that not all of the aerosol that originated from the PSEA was cloud processed, but perhaps passed through cloud turrets. This is equivalent to setting the multiplier in the second term on the rhs of Eq. (3) 5 to 1 , rather than $1-F$. The results of the calculation are shown as blue curves and still indicate an excess of $\mathrm{CN}$ observed compared to the predicted concentration. There is no doubt that all of the aerosol that originated from the sub-cloud layer has been cloud processed as the only way which air can make its way from the sub-cloud layer to the free troposphere (where the cloud-detrained $\mathrm{CN}$ observations were obtained) is 10 via convection.

To examine where the new particles were formed, time series of the difference in particle concentration of the TSI counters was examined. The difference in concentration as measured by the TSI-3010 and TSI-3025 represents the concentration of particles in the approximate size range $1.3 \mathrm{~nm} \leq r \leq 6 \mathrm{~nm}$. Peaks in a timeseries of par15 ticle number concentration difference are indicative of new particle production (Warren and Seinfeld, 1985; Schröder and Ström, 1997; Weber et al., 2001). The time series of the concentration difference is shown for all cloud traverses in Fig. 5. No systematic peaks are located near cloud boundaries or in the cloud outflow. If particle production was occurring near cloud, then measurable particle production would be evident in Fig. 5 as spikes in these regions. A peak is evident on the upwind side of Leg 6, indicating a location of new particle formation, however, this is well above the PSEA and can, therefore, not be the source of new particles. The fact that no systematic particle production is evident near the cloud boundaries, and that numerical calculations predict the majority of $\mathrm{CN}$ to be scavenged in-cloud, yet $\mathrm{CN}$ are still measured, raises the possibility that the particles were formed within cloud. If $\mathrm{CN}$ were formed within cloud then, in the present case, their rate of formation must be less than their rate of loss due to Brownian diffusion, since a deficit of particles was observed compared to the predicted concentration.

It is interesting that the horizontal profiles of the difference between the two TSI
ACPD

$6,7471-7497,2006$

\section{New particle formation in cloud}

J. R. Peter et al.

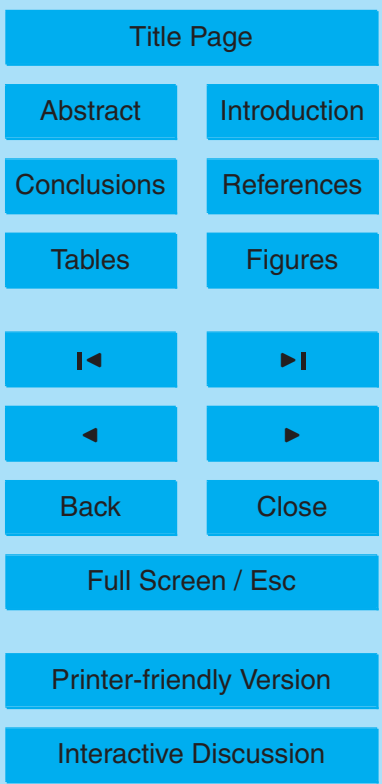

EGU 
counters exhibit large peaks within cloud. One may be tempted to surmise, on these observations alone, that new particles were formed within the cloud. However, Weber et al. (1998) concluded that many observations of particle formation within clouds, relying solely on observations of counts, were spurious due to shattering of cloud droplets 5 impacting the aerosol inlet. In the present study, we have circumvented the confounding effects of droplet shattering because only clear-air samples were considered in the calculations.

A possible mechanism for CN formation within cloud was proposed by Hegg (1991) but, due to the problem of droplet shattering, has received little attention since. Hegg 10 (1991) observed and modelled a case of particle production within cloud and attributed it to heterogeneous nucleation of $\mathrm{H}_{2} \mathrm{SO}_{4}-\mathrm{H}_{2} \mathrm{O}$ droplets. He hypothesized that the enhanced actinic flux within cloud could produce high concentrations of $\mathrm{OH}$ radicals such that the gas-phase supply rate of $\mathrm{H}_{2} \mathrm{SO}_{4}$ (due to oxidation of $\mathrm{SO}_{2}$ by $\mathrm{OH}$ ) was large enough to compensate for the diffusional sink of $\mathrm{H}_{2} \mathrm{SO}_{4}-\mathrm{H}_{2} \mathrm{O}$ to cloud droplets.

15 Several studies reported observations of enhanced $\mathrm{H}_{2} \mathrm{SO}_{4}$ concentration and new particle formation in the vicinity of clouds (Hegg et al., 1990; Perry and Hobbs, 1994; Weber et al., 2001, e.g.). The conclusion implicit in these studies was that new particle formation was occurring, in clear-air regions near the cloud. Weber et al. (2001) concluded that the increased $\mathrm{H}_{2} \mathrm{SO}_{4}$ and $\mathrm{CN}$ concentrations were due to the increase of actinic flux in clear-air near the cloud. However, it is also possible that, if the production rate of $\mathrm{H}_{2} \mathrm{SO}_{4}$ and $\mathrm{CN}$ within cloud was greater than their diffusional sink, then increased concentrations of $\mathrm{H}_{2} \mathrm{SO}_{4}$ and freshly nucleated particles would be observed near clouds. As such, observations of new particle formation near cloud may be the "left over" particles that have spent insufficient time within cloud to be scavenged. An additional feature of Fig. 5 is that large $\mathrm{CN}$ concentrations are not always congruent with high LWC inside cloud. It is, therefore, possible that new particles are formed in areas of low LWC within cloud, where the actinic flux may be sufficiently high to produce the required acid supersaturations, but with low cloud droplet surface area.

Recently Lee et al. (2004) observed high CN particle concentrations in tropical cir-

\section{New particle formation in cloud}

J. R. Peter et al.

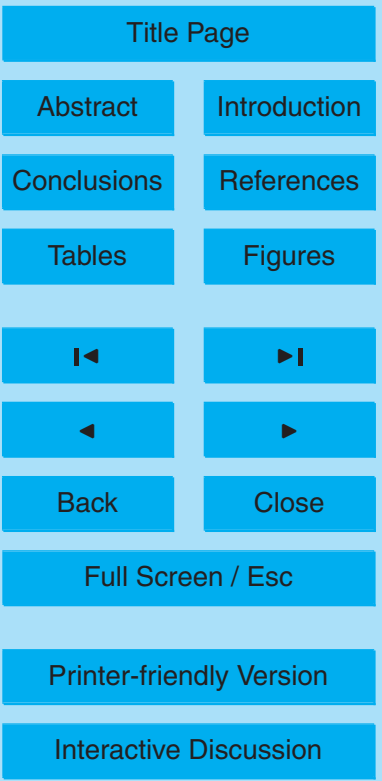


rus clouds synchronous with high ice water contents. They hypothesized that binary homogeneous nucleation and ion-induced nucleation played a significant role in the formation of new particles in these clouds. A model study by Ekman et al. (2006) found formation of nucleation mode $\mathrm{CN}\left(r_{p} \leq 5.84 \mathrm{~nm}\right)$ inside cloud in small quantities, even 5 neglecting the increased in-cloud actinic flux. We are unsure of the exact mechanism of new particle formation in the present case but, the fact that new particle formation has been observed in three dynamically different cloud types (cirrus, stratocumulus and cumulus c.f Lee et al., 2004; Hegg, 1991, and present study) and that a model study has hinted at the possibility of particle formation in a convective cloud (Ekman et al.,

10 2006) necessitates that the process of in-cloud new particle formation be investigated further, especially in light of its important climatological consequences.

\section{Conclusions}

We used a thermodynamic mixing diagram (Paluch, 1979) to determine the sources of cloud-processed air detrained on the downwind side of a cumulus band. The detrained 15 air was found to consist of $\sim 65 \%$ air from the sub-cloud layer and the remainder from air that had been entrained from the free troposphere on the upwind side of the cloud and subsequently been detrained on the downwind side. The mixing analysis enabled a prediction of $\mathrm{SO}_{2}$ and condensation nuclei (CN) concentrations based on, their concentrations in the source regions and assuming that they mix in the same fraction as $20\left\{\theta_{q}, Q\right\}$. The assumption that $\mathrm{SO}_{2}$ and $\mathrm{CN}$ mix in the same fraction as conserved quantities is equivalent to considering that they experience no processing within cloud, even though it was apparent from the mixing analysis that the detrained air passed through cloud. A comparison of the predicted concentrations of $\mathrm{SO}_{2}$ and $\mathrm{CN}$ was then made with those observed, to examine in-cloud processes which modify the aerosol size distribution, namely; (1) the conversion of sulfur dioxide to sulfate within cloud and, (2) the coagulation of unactivated interstitial $\mathrm{CN}$ to cloud droplets.

$\mathrm{SO}_{2}$ and $\mathrm{CN}$ concentrations observed in the cloud-processed detrained air were

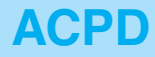

$6,7471-7497,2006$

\section{New particle formation in cloud}

J. R. Peter et al.

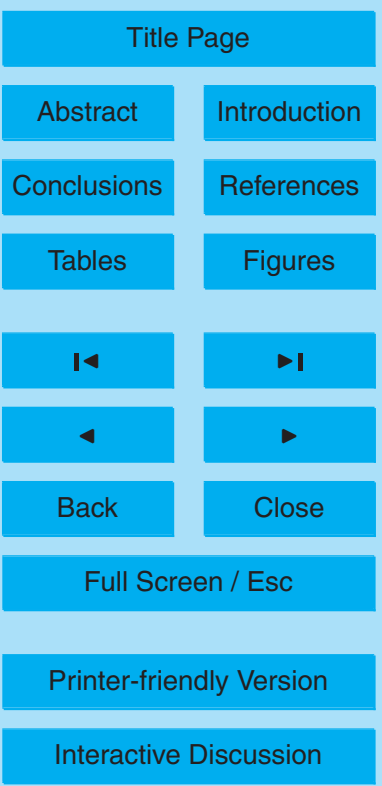


found to be in deficit with those predicted from the mixing analysis. The deficit between the observed and predicted concentrations of $\mathrm{SO}_{2}$ and $\mathrm{CN}$ was attributed to cloud processing. The amount of $\mathrm{SO}_{2}$ scavenged within cloud (assumed to be converted to sulfate via aqueous-phase oxidation) was calculated. The observations and model 5 calculations were analysed to examine where the produced sulfate resided on the detrained aerosol particle size distribution. Furthermore, a model was used to examine if the deficit between the observed and predicted concentration of $\mathrm{CN}$ particles could be explained by Brownian diffusion of the $\mathrm{CN}$ to cloud droplets. The conclusions are summarised as follows:

1. The amount of $\mathrm{SO}_{2}$ scavenged in cloud was calculated to be $1.20 \pm 0.21 \mu \mathrm{g} \mathrm{m}^{-3}$.

2. The $\mathrm{SO}_{2}$ was assumed to be converted to sulfate. The increased mass of sulfate on the detrained aerosol size distribution was found to primarily effect the size of the smallest activated aerosol. All aerosol particles experienced some scavenging due to cloud droplet coalescence, however, the mass increase of the smallest activated aerosol, due to addition of sulfate, compensated for loss due to cloud droplet coalescence.

3. Numerical calculation predicted that the majority of unactivated $\mathrm{CN}$, interstitial in cloudy air, is scavenged due to Brownian diffusion to cloud droplets. This was in contrast to observations which showed $\mathrm{CN}$ to be present in the detrained air, though their number concentration was still less than that predicted by mixing. Moreover, since the observed concentration of $\mathrm{CN}$ observed was greater than predicted when Brownian diffusion was accounted for, it was concluded that there was a source of new CN. Examination of timeseries of the concentration difference of the two $\mathrm{CN}$ counters (operating at differing threshold radii) did not indicate new particle formation in clear air regions around the cloud. The only other possible source of the new $\mathrm{CN}$ was the supersaturated cloud environment. The analysis did not reveal the mechanism of nucleation, though increased actinic fluxes within cloud appeared the most likely mechanism. New particle formation within

\section{New particle formation in cloud}

J. R. Peter et al.

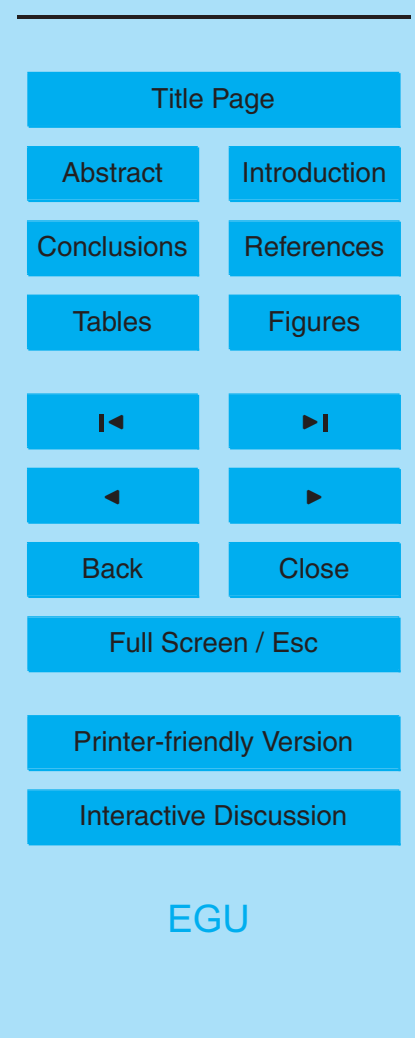


clouds has major implications for the climatology of the tropospheric aerosol and will receive further attention.

Acknowledgements. We thank S.-H. Lee for useful discussions and making her manuscript available before publication. The ACE-Asia Experiment was established with funding from

5 Japan Science and Technology Corporation through its CREST Research Project, the Australian Research Council through Monash University, the Commonwealth of Australia's Major National Research Facilities Program through ARA-Airborne Research Australia and the Commonwealth Scientific and Industrial Research Organisation of Australia through its Office of Space Science and Applications and CSIRO Atmospheric Research. This work was supported 10 in part by funding from the Japan Science and Technology Corporation, the CREST program 1999-2004 (Chief Scientist: T. Nakajima, CCSR, University of Tokyo). Thanks to H. Minda and M. Adhikari, HyARC, Nagoya University for $\mathrm{SO}_{2}$ data collection aboard the aircraft and data analysis. Thanks also to P. Krummel (CSIRO) for technical assistance with data presentation. This work has been supported by an ARC large grant, and a Monash University Departmental

15 Scholarship. Part of the work was done while the first author held an NCAR ASP Graduate Fellowship. NCAR is supported by the National Science Foundation.

\section{References}

Albrecht, B.: Aerosols, cloud microphysics, and fractional cloudiness, Science, 245, 12271230, 1989. 7473

Bahreini, R., Jiminez, J., Wang, J., Flagan, R., Seinfeld, J., Jayne, J., and Worsnop, D.: Aircraft-based aerosol size and composition measurements during ACE-Asia using an Aerodyne aerosol mass spectrometer, J. Geophys. Res., 108, 8645, doi:10.1029/2002JD003226, 2003. 7479

Birmili, W., Yuskiewicz, B., Wiedensohler, A., Stratmann, F., Choularton, T., and Bower, K.: Climate-relevant modification of the aerosol size distribution by processes associated with orographic clouds, Atmos. Res., 50, 241-263, 1999. 7478

Bower, K. and Choularton, T.: Cloud processing of the cloud condensation nucleus spectrum and its climatological consequences, Q. J. R. Meteorol. Soc., 119, 655-679, 1993. 7480

Charlson, R., Schwartz, S., Hales, J., Cess, R., Coakley, J., Hansen, J., and Hofmann, D.: Climate forcing by anthropogenic aerosols, Science, 255, 423-430, 1992. 7472

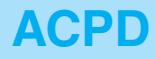

$6,7471-7497,2006$

\section{New particle formation in cloud}

J. R. Peter et al.

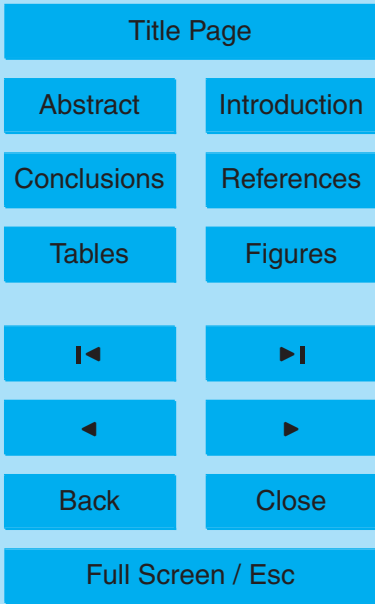

Printer-friendly Version

Interactive Discussion 
Choularton, T., Bower, K., and Gallagher, M.: The effect of sulphur chemistry on the scattering properties of particles, Phil. Trans. R. Soc. Lond. B, 352, 213-220, 1997. 7480

Clarke, A., Varner, J., Eisele, F., Mauldin, R., and Tanner, D.: Particle production in the remote marine atmosphere: Cloud outflow and subsidence during ACE 1, J. Geophys. Res., 103, $5 \quad$ 16397-16409, 1998. 7474

Clement, C., Ford, I., Twohy, C., Weinheimer, A., and Campos, T.: Particle production in the outflow of a midlatitude storm, J. Geophys. Res., 107, 4559, doi:10.1029/2001JD001352, 2002. 7474

Coakley, J., Cess, R., and Yurevich, F.: The effect of tropspheric aerosols on the earth's radiation budget: a parameterization for climate models, J. Atmos. Sci., 40, 116-138, 1983. 7472

Dahneke, B.: Simple kinetic theory of Brownian diffusion in vapors and aerosols, in: Theory of Dispursed Multiphase Flow, edited by: Meyer, R., 97-138, Academic Press, New York, 1983. 7482

15 Ekman, A., Wang, C., Ström, J., and Krejci, R.: Explicit simulations of aerosol physics in a cloud-resolving model: aerosol transport and processing in the free troposphere, J. Atmos. Sci., 63, 682-696, 2006. 7486

Gervat, G., Clark, P., marsh, A., Teasdale, I., Chandler, A., Choularton, T., Gay, M., Hill, M., and Hill, T.: Field evidence for the oxidation of $\mathrm{SO}_{2}$ by $\mathrm{H}_{2} \mathrm{O}_{2}$ in clouds, Nature, 241-243, 1988. $20 \quad 7473$

Hegg, D.: Particle production in clouds, Geophys. Res. Lett., 18, 995-998, 1991. 7474, 7485, 7486

Hegg, D. and Hobbs, P.: Measurements of sulfate production in natural clouds, Atmos. Environ., 16, 2663-2668, 1982. 7473

Hegg, D., Hobbs, P., and Radke, L.: Measurements of the scavenging of sulfate and nitrate in clouds, Atmos. Environ., 18, 1939-1946, 1984. 7478

Hegg, D., Radke, L., and Hobbs, P.: Particle production associated with marine clouds, J. Geophys. Res., 95, 13917-13926, 1990. 7485

Hegg, D., Radke, L., and Hobbs, P.: Measurements of Aitken nuclei and cloud condensation nuclei in the marine atmosphere and their relation to the DMS-cloud-climate hypothesis, $\mathrm{J}$. Geophys. Res., 26, 18727-18733, 1991. 7474

Hoppel, W., Frick, G., and Larson, R.: Effect of nonprecipitating clouds on the aerosol size distribution in the marine boundary layer, Geophys. Res. Lett., 13, 125-128, 1986. 7473

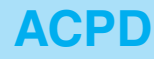

$6,7471-7497,2006$

\section{New particle formation in cloud}

J. R. Peter et al.

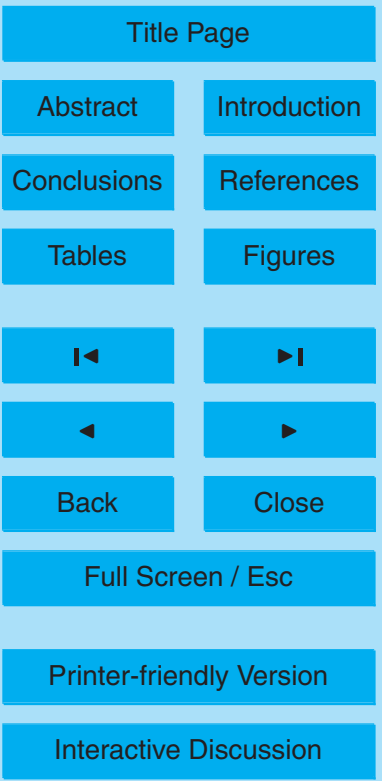


Husain, L., Ghauri, B., Yang, K., Khan, A., and Rattigan, O.: Application of the $\mathrm{SO}_{4}{ }^{2-} / \mathrm{Se}$ tracer technique to study $\mathrm{SO}_{2}$ oxidation in cloud and fog on a time scale of minutes, Chemosphere, 54, 177-183, 2004. 7478

Jensen, J., Austin, P., Baker, M., and Blyth, A.: Turbulent mixing, spectral evolution and dynamics in a warm cumulus cloud, J. Atmos. Sci., 42, 173-192, 1985. 7476

Krämer, M., Beltz, N., Schell, D., Schütz, L., Spengard-Eichel, C., and Wurzler, S.: Cloud processing of continental aerosol particles: Experimental investigations for different drop sizes, J. Geophys. Res., 105, 11739-11752, 2000. 7480

Leaitch, W.: Observations pertaining to the effect of chemical transformation in cloud on the anthropogenic aerosol size distribution, Aerosol Sci. Technol., 16, 157-173, 1996. 7480

Lee, S., Wilson, J., Baumgardner, D., Herman, R., Weinstock, E., Lafleur, B., Kok, G., Anderson, B., Lawson, P., Baker, B., Strawa, A., Pittman, J., Reeves, J., and Bui, T.: New particle formation observed in the tropical/subtropical cirrus clouds, J. Geophys. Res., 109, D20209, 2004. 7485,7486

Lelieveld, J. and Heintzenberg, J.: Sulfate cooling effect on climate through in-cloud oxidation of anthropogenic $\mathrm{SO}_{2}$, Science, 258, 117-120, 1992. 7473

Liu, P., Leaitch, W., Macdonald, A., Isaac, G., Strapp, J., and Wiebe, H.: Sulphate production in summer cloud over Ontario, Canada, Tellus, 45B, 368-389, 1993. 7478

Madronich, S.: Photodissociation in the atmosphere. 1. Actinic flux and the effects of ground reflections and clouds, J. Geophys. Res., 92, 9740-9752, 1987. 7474

O'Dowd, C., Lowe, J., and Smith, M.: Observations and modelling of aerosol growth in marine stratocumulus - case study, Atmos. Environ., 33, 3053-3062, 1998. 7478

Paluch, I.: The entrainment mechanism in Colorado cumuli, J. Atmos. Sci., 36, 2462-2478, 1979. 7476,7486

25 Perry, K. and Hobbs, P.: Further evidence for particle nucleation in clear air adjacent to marine cumulus clouds, J. Geophys. Res., 99, 22 803-22 818, 1994. 7474, 7485

Peter, J., Siems, S., Jensen, J., Gras, J., Ishizaka, Y., and Hacker, J.: Prediction and observation of cloud processing of the aerosol size distribution by a band of cumulus, Q. J. R. Meteorol. Soc., 845-864, 2006. 7477, 7481, 7493

Pilinis, C. and Seinfeld, J.: Continued development of a general equilibrium model for inorganic multicomponent atmospheric aerosols, Atmos. Environ., 21, 2453-2466, 1987. 7479

Radke, L. and Hobbs, P.: Humidity and Particle Fields Around Small Cumulus Clouds, J. Atmos. Sci., 48, 1190-1193, 1991. 7474

\section{New particle formation in cloud}

J. R. Peter et al.

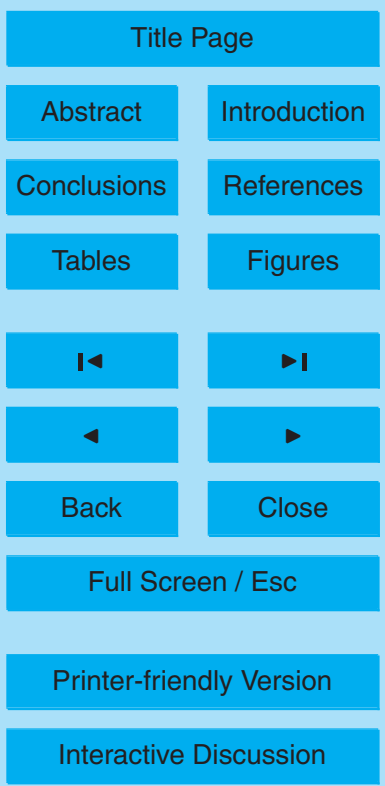


Schröder, F. and Ström, J.: Aircraft measurements of sub micrometer aerosol particles $(>7 \mathrm{~nm})$ in the midlatitude free troposphere and tropopause region, Atmos. Res, 44, 333-356, 1997. 7484

Seinfeld, J. and Pandis, S.: Atmospheric chemistry and physics; from air pollution to climate change, John Wiley and Sons, Inc., New York, 1998. 7473, 7482

Twohy, C., Clement, C., Gandrud, B., Weinheimer, A., Campos, T., Baumgardner, D., Brune, W., Faloona, I., Sachse, G., Vay, S., and Tan, D.: Deep convection as a source of new particles in the midlatitude upper troposphere, J. Geophys. Res., 107, 4560, doi:10.1029/ 2001JD000323, 2002. 7474

10 Twomey, S.: The influence of pollution on the shortwave albedo of clouds, J. Atmos. Sci., 34, 1149-1152, 1977. 7473

Warren, D. and Seinfeld, J.: Prediction of aerosol concentration resulting from a burst of nucleation, J. Colloid. Interface Sci., 105, 136-142, 1985. 7484

Weber, R., Clarke, A., Litchy, M., Li, J., Kok, G., Schillawski, R., and McMurry, P.: Spurious 15 aerosol measurements when sampling from aircraft in the vicinity of clouds, J. Geophys. Res., 103, 28337-28346, 1998. 7485

Weber, R., Chen, G., Davis, D., III, R. M., Tanner, D., Eisele, F., Clarke, A., Thornton, D., and Bandy, A.: Measurements of enhanced $\mathrm{H}_{2} \mathrm{SO}_{4}$ and 3-4 nm particles near a frontal cloud during ACE 1, J. Geophys. Res., 106, 24 107-24 117, 2001. 7474, 7484, 7485 T., Wells, M., Parkin, M., Acker, K., Wieprecht, W., Facchini, M., Lind, J., Fuzzi, S., Arends, B., and Kulmala, M.: Night-time formation and occurrence of new particles associated with orographic clouds, Atmos. Environ., 31, 2545-2559, 1997. 7474

Yuskiewicz, B., Stratmann, F., Birmili, W., Wiedensohler, A., Swietlicki, E., Berg, O., and Zhou, J.: The effects of in-cloud mass production on atmospheric light scatter, Atmos. Res, 50, 265-288, 1999. 7473

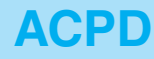

$6,7471-7497,2006$

\section{New particle formation in cloud}

J. R. Peter et al.

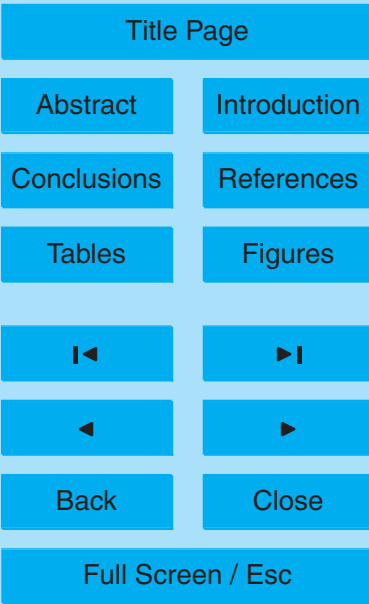

Printer-friendly Version

Interactive Discussion 


\section{ACPD}

$6,7471-7497,2006$

\section{New particle formation in cloud}

J. R. Peter et al.

Table 1. Concentration of $\mathrm{SO}_{2}$ and $\mathrm{CN}$ near cloud.

\begin{tabular}{lccccc}
\hline & Sub cloud & $\begin{array}{c}\text { Entrained } \\
\text { from PSEA }\end{array}$ & Detrained & $\begin{array}{c}\text { Predicted } \\
\text { processed }^{\mathrm{c}}\end{array}$ & Cloud \\
\hline $\mathrm{SO}_{2}^{\mathrm{a}}$ & $7.79 \pm 0.14$ & $2.36 \pm 0.10$ & $4.57 \pm 0.12$ & $5.81 \pm 0.17$ & $1.24 \pm 0.21$ \\
$\mathrm{CN}(\mathrm{r} \geq 1.3 \mathrm{~nm})^{\mathrm{b}}$ & $2179 \pm 170$ & $507 \pm 89$ & $1303 \pm 93$ & $1577 \pm 146$ & $274 \pm 239$ \\
$\mathrm{CN}(\mathrm{r} \geq 6 \mathrm{~nm})^{\mathrm{b}}$ & $1807 \pm 94$ & $434 \pm 27$ & $1068 \pm 62$ & $1313 \pm 70$ & $245 \pm 132$ \\
\hline
\end{tabular}

\section{Title Page}

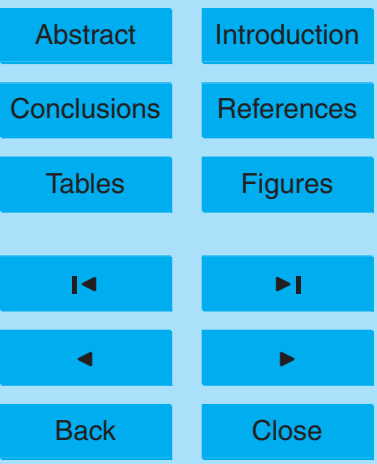

Full Screen / Esc

Printer-friendly Version

Interactive Discussion 


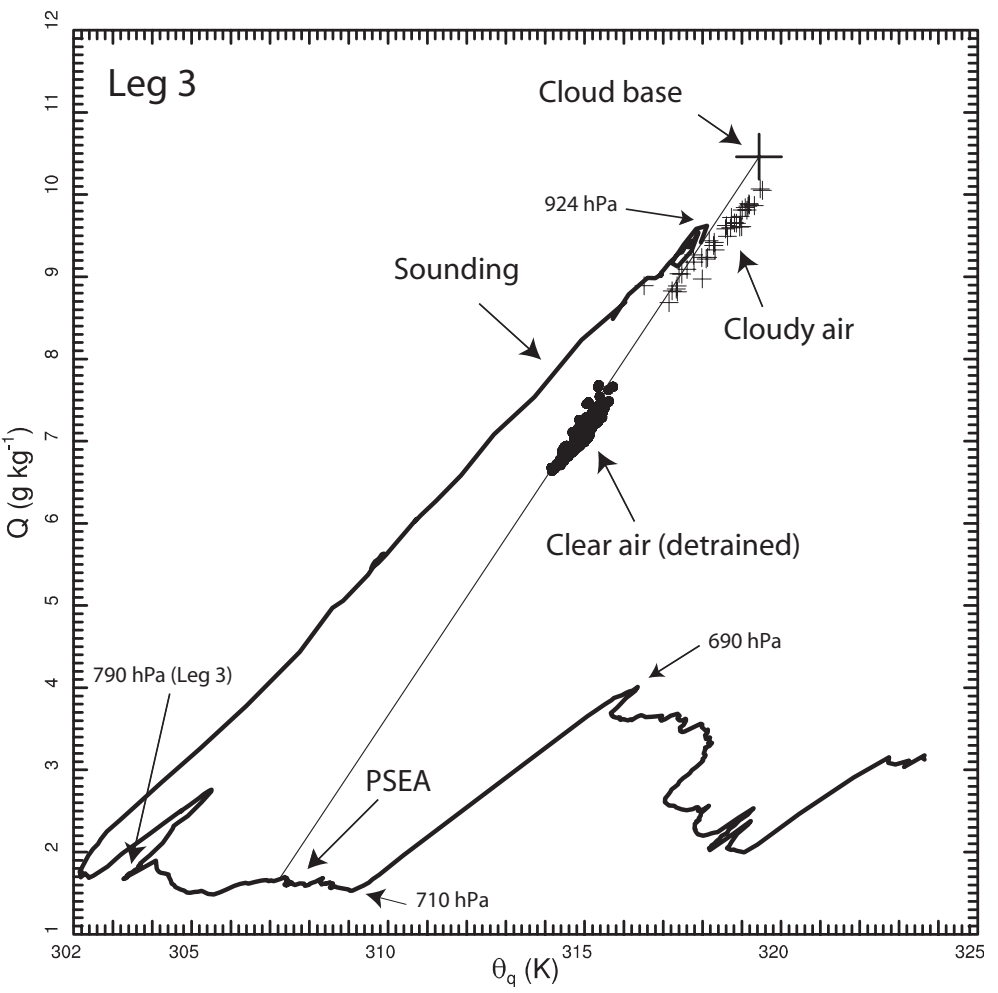

\section{ACPD}

$6,7471-7497,2006$

\section{New particle formation in cloud}

J. R. Peter et al.

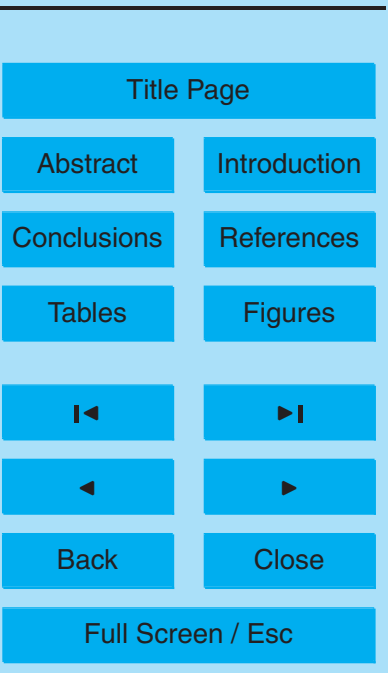

Fig. 1. Mixing diagram of conserved variables, wet-equivalent potential temperature $\left(\theta_{q}\right)$ and total water $(Q)$. Cloud base, sounding, cloudy air and clear air points are labeled. In-cloud and clear air points are $1 \mathrm{~Hz}$ observations. The primary source of entrained air (PSEA) is indicated where the line of best fit between cloud base and the clear air measurements intersect the sounding. The fraction of sub-cloud air $(F)$ is determined by the relative distance of a cloudy or clear air sample between the cloud base sample and the PSEA, and is given by Eq. (2). Reprinted from (Peter et al., 2006) with kind permission of the Royal Meteorological Society. 


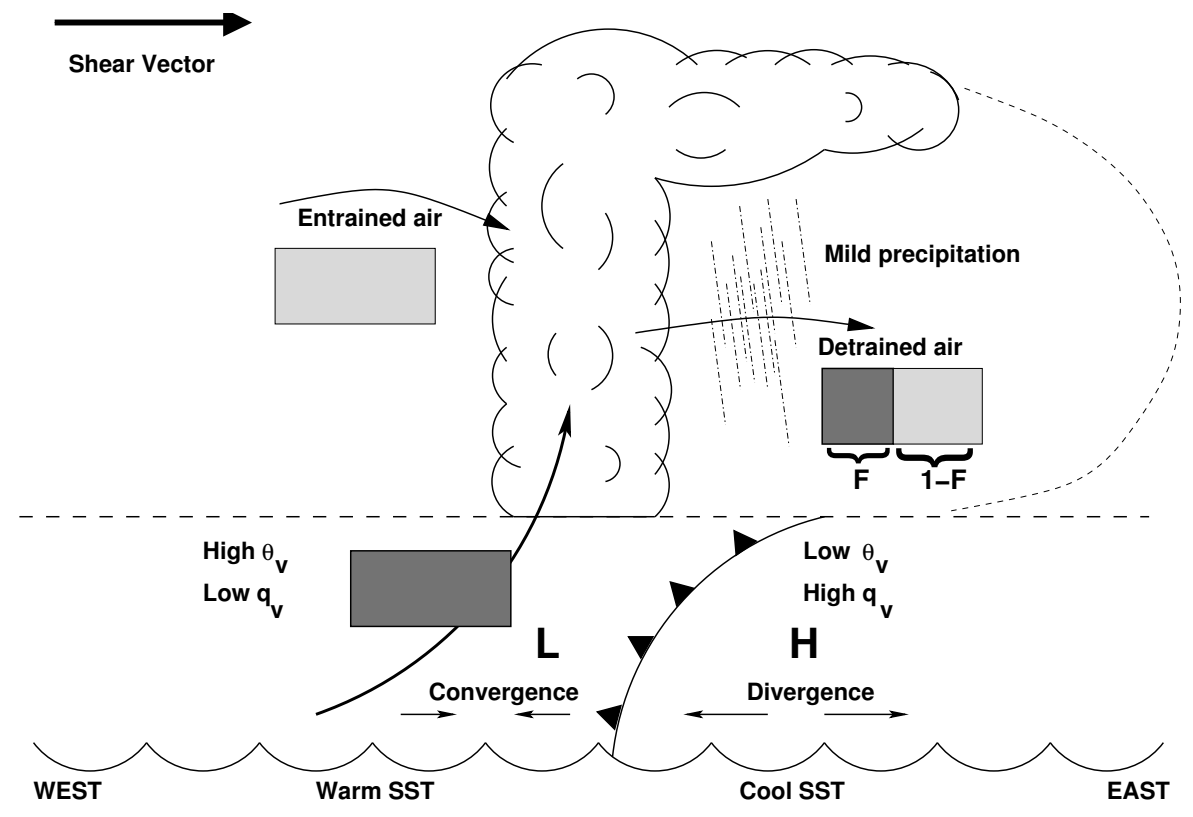

Fig. 2. A schematic of the cumulus dynamics. Sub-cloud air was forced over a cold pool generated by evaporating precipitation. Entrained air was mixed with sub-cloud air and subsequently deposited downwind of the cloud, in the direction of the upper level shear. Analysis of the mixing fraction of $\left\{\theta_{q}, Q\right\}$ samples revealed that the detrained air contained a fraction, $F=0.64$ sub-cloud air and, $1-F=0.36$ entrained air from the PSEA. If gas-phase and aerosol species experience no cloud processing they will mix in the same fraction as the $\left\{\theta_{q}, Q\right\}$ samples.
$6,7471-7497,2006$

\section{New particle formation in cloud}

\section{J. R. Peter et al.}

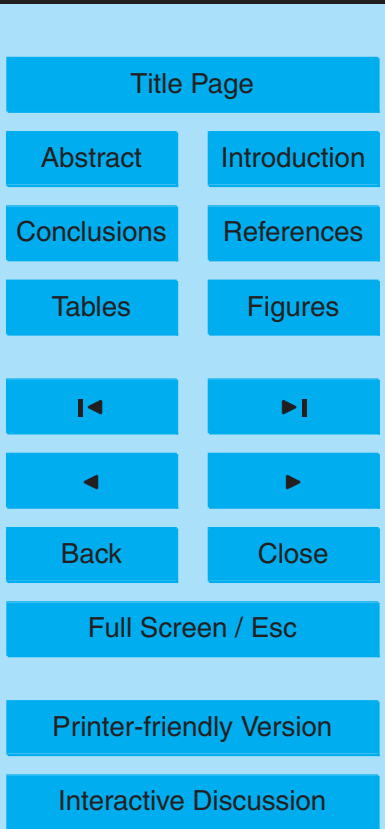




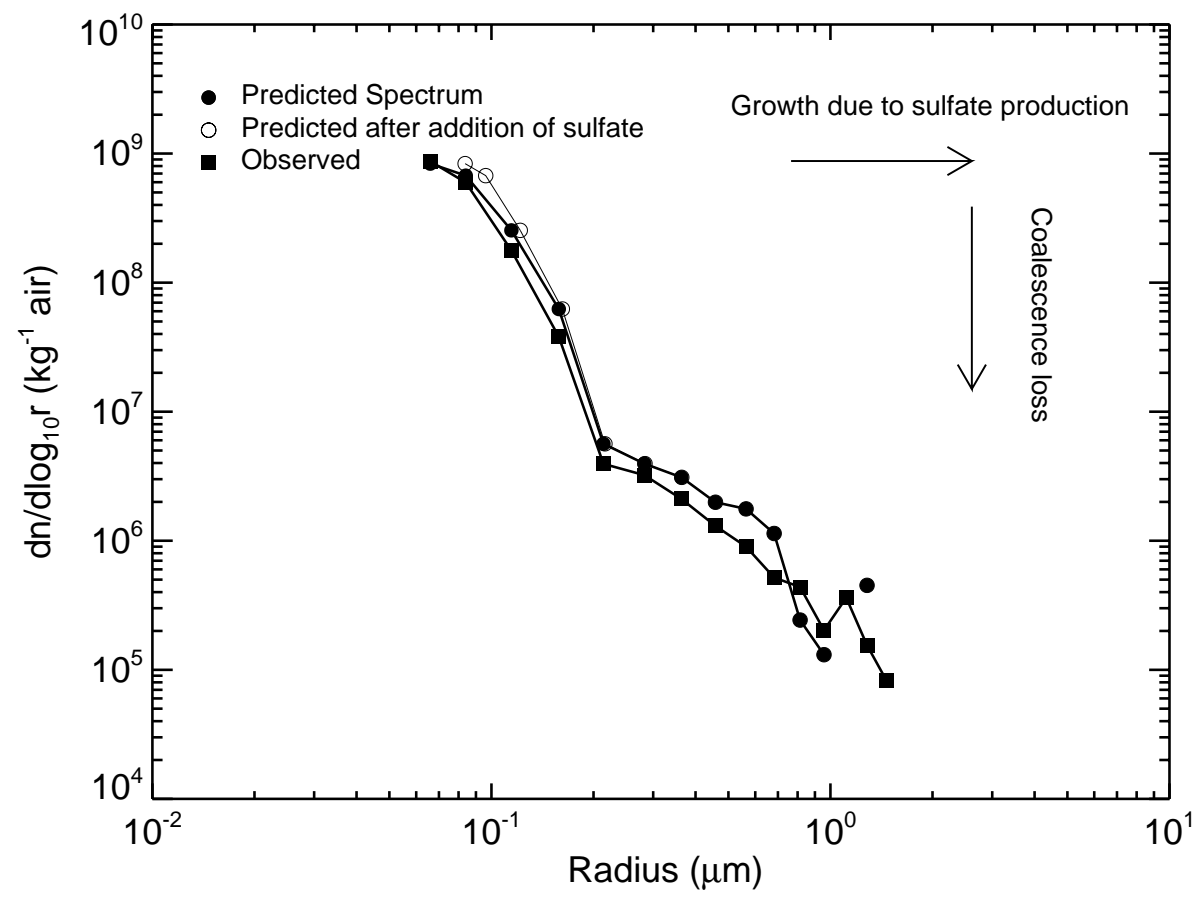

Fig. 3. ASASP aerosol size distribution of the spectra predicted due to mixing, predicted after addition of sulfate and observed. The spectrum due to the addition of sulfate was calculated assuming an accumulation mode aerosol of uniform composition and modified by the addition of $1.24 \pm 0.21 \mu \mathrm{g} \mathrm{m}^{-3}$ of sulfate.

\section{ACPD}

$6,7471-7497,2006$

\section{New particle formation in cloud}

\section{J. R. Peter et al.}

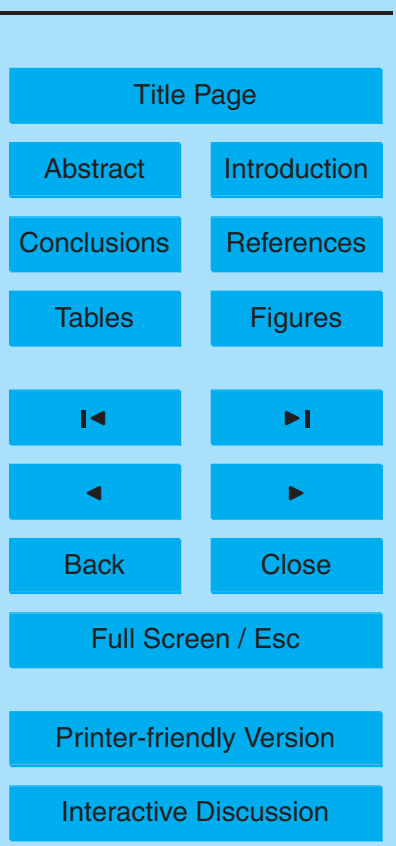




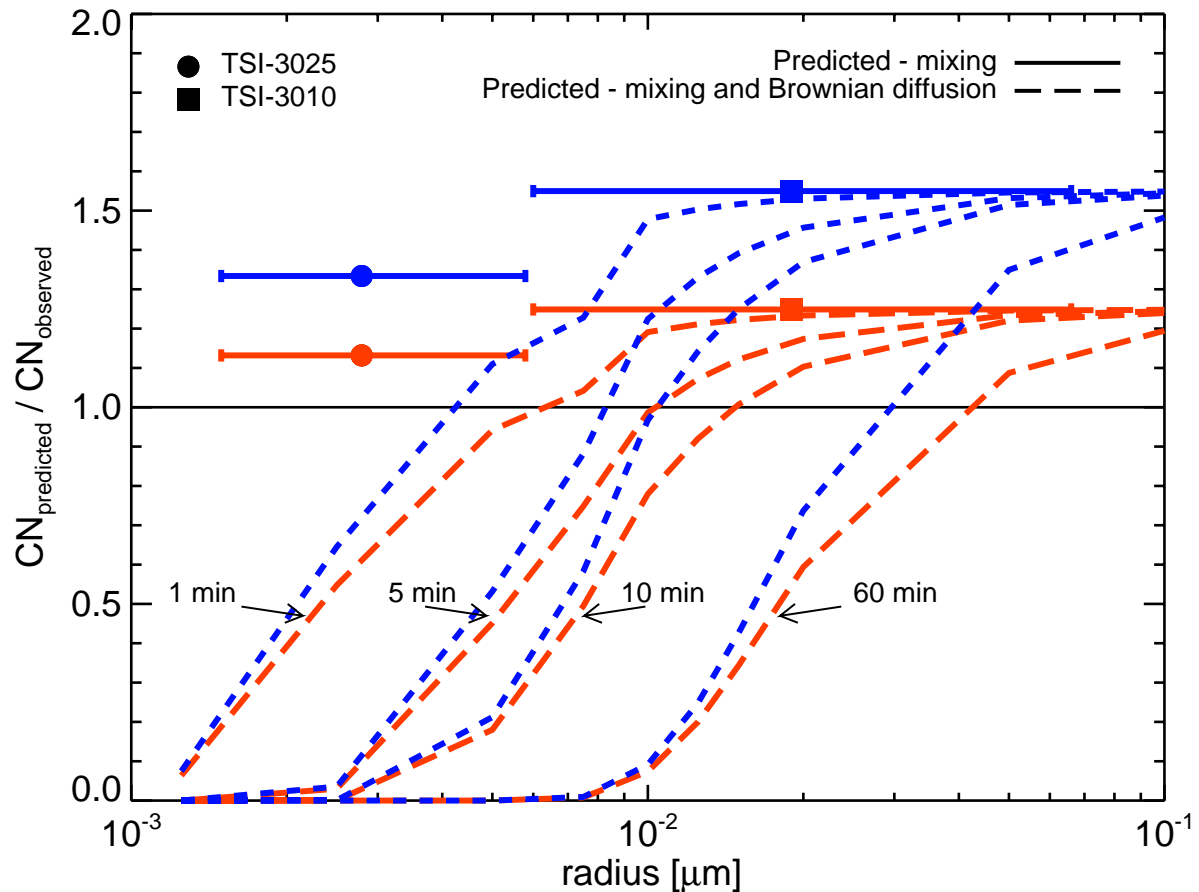

Fig. 4. The ratio of the predicted concentration of $\mathrm{CN}$ to the observed concentration. The ratio is shown for differential concentrations measured by the TSI-3025 $\left(r_{p} \geq 1.3 \mathrm{~nm}\right)$ and TSI-3010 probes $\left(r_{p} \geq 6 \mathrm{~nm}\right)$. The predicted concentration of $\mathrm{CN}$ is $\sim 20 \%$ greater than observed due to the diffusion of the $\mathrm{CN}$ to cloud droplets. The dashed curves show the predicted to observed ratio with inclusion of the effect of Brownian diffusion of $\mathrm{CN}$ to cloud droplets and represent $1 \mathrm{~min}$ to $1 \mathrm{~h}$ of in-cloud time. When Brownian diffusion is taken into account it becomes apparent that few, if any, $\mathrm{CN}$ should be observed in the air detraining from the cloud; evidence of new particle formation.

\section{ACPD}

$6,7471-7497,2006$

\section{New particle formation in cloud}

\section{J. R. Peter et al.}

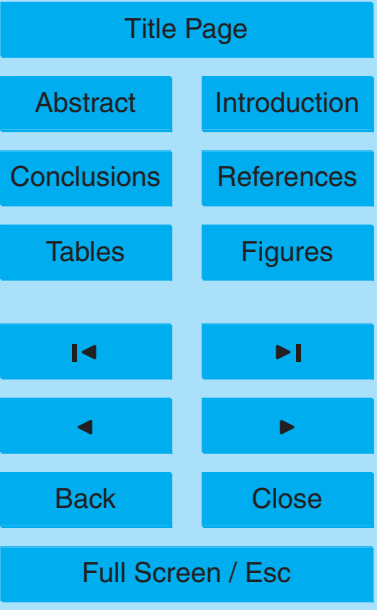

Printer-friendly Version

Interactive Discussion 


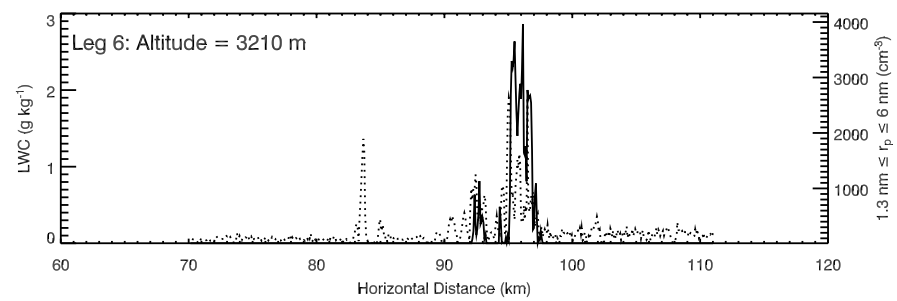

\section{ACPD}

$6,7471-7497,2006$

\section{New particle formation in cloud}

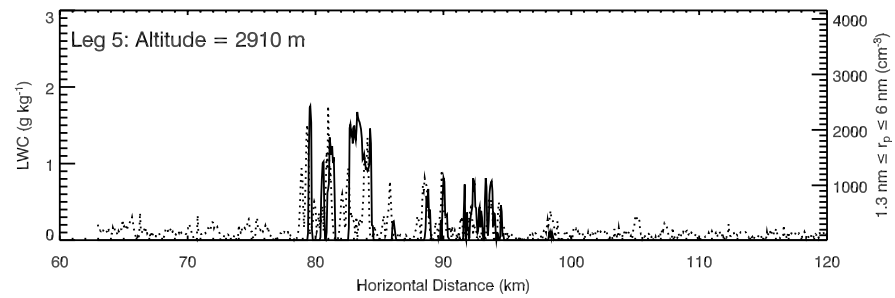

\section{J. R. Peter et al.}
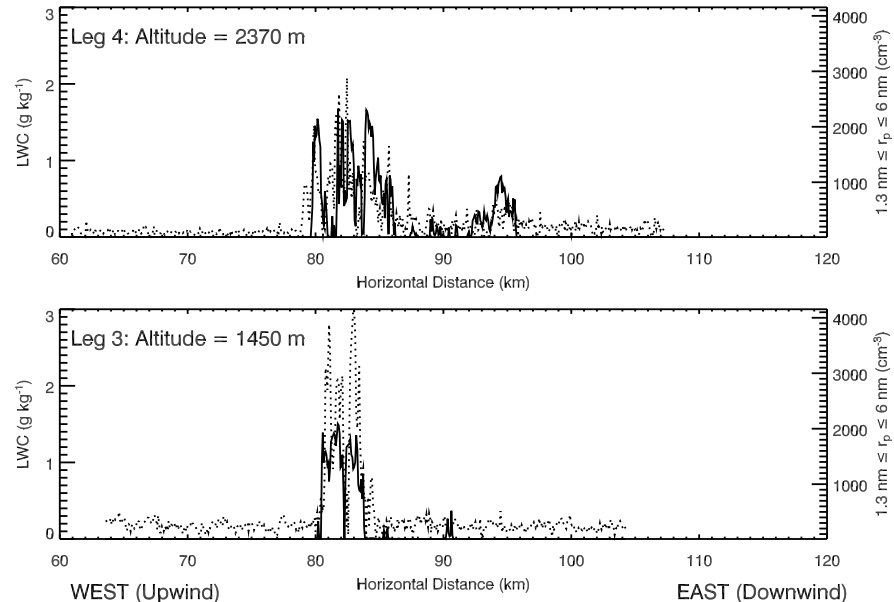

Title Page

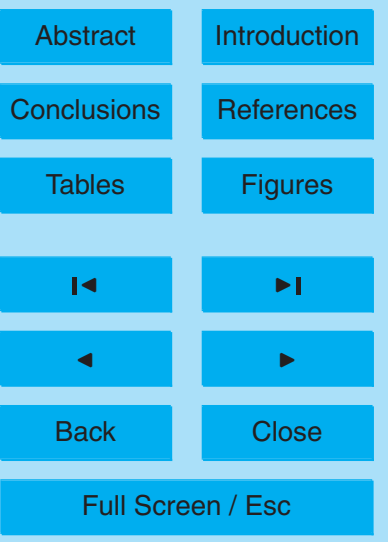

Printer-friendly Version

Interactive Discussion

Fig. 5. Horizontal profiles of the number of particles in the radius interval $1.3 \mathrm{~nm} \leq r_{p} \leq 6 \mathrm{~nm}$ for each of the flight legs through cloud. 